\title{
Dual-acting peptide with prolonged glucagon-like peptide-1 receptor agonist and glucagon receptor antagonist activity for the treatment of type 2 diabetes
}

\author{
Thomas H Claus, Clark Q Pan', Joanne M Buxton, Ling Yang, Jennifer C Reynolds, Nicole Barucci, \\ Michael Burns, Astrid A Ortiz ${ }^{1}$, Steve Roczniak', James N Livingston, Kevin B Clairmont and \\ James P Whelan
}

Bayer HealthCare, Pharmaceuticals, Department of Metabolic Disease Research, 400 Morgan Lane, West Haven, Connecticut 06516 USA

${ }^{1}$ Bayer HealthCare, Biotechnology, 800 Dwight Way, Berkeley, California 94701, USA

(Requests for offprints should be addressed to J P Whelan; Email: james.whelan.b@bayer.com)

\begin{abstract}
Type 2 diabetes is characterized by reduced insulin secretion from the pancreas and overproduction of glucose by the liver. Glucagon-like peptide-1 (GLP-1) promotes glucose-dependent insulin secretion from the pancreas, while glucagon promotes glucose output from the liver. Taking advantage of the homology between GLP-1 and glucagon, a GLP1 /glucagon hybrid peptide, dual-acting peptide for diabetes (DAPD), was identified with combined GLP-1 receptor agonist and glucagon receptor antagonist activity. To overcome its short plasma half-life DAPD was PEGylated, resulting in dramatically prolonged activity in vivo. PEGylated DAPD (PEG-DAPD) increases insulin and decreases glucose in a glucose tolerance test, evidence of GLP-1 receptor
\end{abstract}

agonism. It also reduces blood glucose following a glucagon challenge and elevates fasting glucagon levels in mice, evidence of glucagon receptor antagonism. The PEGDAPD effects on glucose tolerance are also observed in the presence of the GLP-1 antagonist peptide, exendin(9-39). An antidiabetic effect of PEG-DAPD is observed in $d b / d b$ mice. Furthermore, PEGylation of DAPD eliminates the inhibition of gastrointestinal motility observed with GLP-1 and its analogues. Thus, PEG-DAPD has the potential to be developed as a novel dual-acting peptide to treat type 2 diabetes, with prolonged in vivo activity, and without the GI side-effects.

Journal of Endocrinology (2007) 192, 371-380

\section{Introduction}

Glucagon-like peptide-1 (GLP-1) is a potent endogenous modulator of insulin secretion that is released by the L-cells in the crypts of the jejunum and ileum in response to a meal (Kieffer \& Habener 1999). Its function is to prepare the pancreatic $\beta$ cells to respond to the increase in calories with the appropriate release of insulin. Importantly, GLP-1 does not provoke hypoglycemia because it does not stimulate insulin secretion unless the plasma glucose concentration is greater than $5 \mathrm{mM}$ (Holz et al. 1993). Therapies based on this principle would provide a significant advantage over sulfonylureas (SFUs) and meglitinides that stimulate insulin secretion from pancreatic $\beta$-cells through closure of $\mathrm{K}_{\mathrm{ATP}}$ channels, but whose actions are not glucose-dependent (for review, see Rendell 2004).

No small molecule activators of the GLP-1 receptor have been described. This has led to the development of GLP-1 peptide-based therapeutics. GLP-1 itself has a very short halflife $(<5 \mathrm{~min})$ in vivo due to degradation by dipeptidyl peptidase-IV (DPP-IV) and clearance by the kidney (Kieffer et al. 1995). Several inhibitors of DPP-IV, as well as DPPIV-resistant peptide analogues of GLP-1, are in development for the treatment of type 2 diabetes (Weber 2004 and for review, see Knudsen 2004). One frequently observed sideeffect of GLP-1, or its analogues, is nausea and vomiting correlating with the inhibition of gastrointestinal (GI) motility (Buse et al. 2004, Elbrond et al. 2002). This effect may be mediated, at least partially, by GLP-1 activity in the brain (Imeryuz et al. 1997, Wettergren et al. 1998).

Glucagon is a 29 -amino acid peptide secreted by the $\alpha$ cells of the pancreatic islets in response to reduced blood glucose levels (Unger et al. 1978). This hormone travels via the portal blood to the liver where it activates the glucagon receptor. This sets in motion a series of cAMP-mediated events that result in increased hepatic glucose production from both glycogenolysis and gluconeogenesis (Jelinek et al. 1993). Glucose production is inappropriately elevated in type 2 diabetes, which is due to insulin resistance in the liver that reduces the ability of insulin to suppress glucose production, and to the continued release of glucagon in the face of hyperglycemia (Baron et al. 1987, Shah et al. 2000). 
In this study, we aimed to target with a single molecule both the defect in insulin secretion and the glucagonmediated elevation in hepatic glucose production occurring in type 2 diabetes. The feasibility of such an approach is based on the high degree of homology ( $50 \%)$ between GLP-1 and glucagon (Holst 1996). GLP-1/glucagon hybrid peptides that bind to both receptors have been reported previously (Hjorth et al. 1994). However, the agonist or antagonist activity of these hybrid peptides on the GLP-1 or glucagon receptors was not demonstrated. Taking advantage of the high degree of sequence homology between GLP-1 and glucagons, we recently described the identification of a series of GLP-1/glucagon hybrid peptides that had both GLP-1 agonist and glucagon antagonist activity in vitro (Pan et al. 2006). Here, we report that the optimal hybrid peptide described previously (ANC7K2), which we now refer to as dual-acting peptide for diabetes (DAPD), has both GLP-1 agonist and glucagon antagonist activity in vivo.

One approach to prolonging the in vivo half-life of a protein is PEGylation, the covalent attachment to a target molecule of long-chained polyethylene glycol (PEG) molecules produced by linking repeating units of ethylene oxide (Harris et al. 2001). PEGylation significantly increases the in vivo half-life by protecting the protein from protease digestion and by keeping the material out of the kidney filtrate. PEGylation of DAPD with high molecular mass PEG (43 kDa) prolonged the in vivo duration of action of the hybrid peptide, and had the added feature of eliminating the GI side-effects.

\section{Materials and Methods}

\section{Peptide synthesis and PEGylation}

GLP-1, glucagon, FA-GLP-1, and DAPD were supplied by Sigma Genosys or SynPep. The peptides were characterized by HPLC and mass spectrometry and were $>90 \%$ pure (data not shown). DAPD was site-specifically PEGylated at the C-terminal cysteine with 22, 33, or 43 kDa PEG-maleimide purchased from Nektar Therapeutics (San Carlos, CA, USA) and purified to $>95 \%$ purity (data not shown).

\section{Animals}

Male $B A L B / c$ mice $(20-25 \mathrm{~g})$ were purchased from Charles River Laboratories (Wilmington, MA, USA). Male Wistar rats $(220-250 \mathrm{~g})$ were purchased from Harlan (Indianapolis, IN, USA). Female $d b / d b$ mice C57BLKS/J Lepr ${ }^{\mathrm{db}} /$ Lepr $^{\mathrm{db}}$ were purchased from The Jackson Laboratory (Bar Harbor, ME, USA) at 5-6 weeks of age. All animals were maintained on standard laboratory rodent chow available ad libitum for at least 5 days before being used in an experiment. All procedures were approved by the Bayer Animal Care and Use Committee and all experiments were performed in accordance with relevant guidelines and regulations.

\section{i.p. Glucose tolerance test (IPGTT)}

The IPGTT was performed in male $B A L B / c$ mice or male Wistar rats as previously described (Pan et al. 2006). Briefly, mice or rats were either fasted overnight and then given peptide or vehicle by s.c. injection or they were given peptide or vehicle first and then fasted overnight, depending on the time interval between dosing and when the IPGTT was to be performed. At the appropriate time after dosing, the fasting blood glucose level was measured from tail-tip blood using a Glucometer (Bayer HealthCare) and the animals were given $2 \mathrm{~g} / \mathrm{kg}$ glucose by i.p. injection. Blood glucose was measured again after 15, 30, and $60 \mathrm{~min}$. The area under the glucose curve (AUC) was calculated using the trapezoidal method, and the effect of the peptide on the AUC was expressed as a percentage of the AUC for the vehicle-treated group. When insulin levels were measured, blood (80-100 $\mu \mathrm{l})$ was collected by retro-orbital puncture and plasma insulin levels were determined with a mouse insulin ELISA kit (Alpco Diagnostics, Salem, NH, USA).

\section{Gastrointestinal motility in mice and rats}

Male $B A L B / c$ mice or male Wistar rats were either fasted overnight first and then given peptide or vehicle by s.c. injection or they were given peptide or vehicle first and then fasted overnight, depending on the time interval between dosing and the measurement of motility. At the appropriate time after dosing, the mice were given a charcoal meal $(10 \%$ charcoal, 5\% gum Arabic, and 1\% carboxymethylcellulose in a volume of $0.8 \mathrm{ml}$ ) by oral gavage and then euthanized by cervical dislocation $5 \mathrm{~min}$ later. The small intestine was dissected out and the length of the intestine measured as well as the length of the charcoal traveled past the pyloric sphincter. The percentage traveled was calculated by dividing the distance the charcoal traveled by the total length of the small intestine and multiplying by 100 .

Gastrointestinal motility in rats following peptide administration by i.c.v. injection

Male Wistar rats (275-350 g) were anesthetized with isoflurane gas, and a single $21 \mathrm{G}$ stainless steel cannula was aimed at the brain third ventricle using a stereotaxic instrument and the following coordinates: $-2 \cdot 2 \mathrm{~mm}$ posterior from the bregma and $-7.5 \mathrm{~mm}$ ventral to the dura. The cannula was secured to the skull with jeweler's screws and dental cement. One week after surgery, cannula placement was tested by infusion of $1 \mu \mathrm{l}$ of $10 \mathrm{ng} / \mu \mathrm{l}$ angiotensin II. Animals that drank $5 \mathrm{ml}$ or more of water in an 1-h period were retained for the study. On the day of the gastric motility experiment, $10 \mu \mathrm{l}$ vehicle (PBS), GLP-1 (7-36) amide peptide, or PEG-DAPD were infused into the third ventricle of overnight fasted rats using an infusion pump (Harvard Apparatus, Holliston, MA, USA). Peptides or vehicle were infused for $2 \mathrm{~min}$ and the injection needle was kept in place for an additional minute. 
Five minutes post-infusion GI motility was measured as described previously. After the experiment, correct placement of the cannula was verified by injection of Evans Blue followed by brain sectioning.

\section{Glucagon-stimulated glucose production in fed $\mathrm{BALB} / \mathrm{c}$ mice}

Fed male $B A L B / c$ mice were given a s.c. injection of vehicle (PBS), PEG-GLP-1, or PEG-DAPD and food was withheld. Two hours and forty-five minutes later, the mice were given an i.p. injection of saline or $10 \mathrm{mg} / \mathrm{kg}$ somatostatin (SRIF). Fifteen minutes later (zero time), the mice were given another i.p. injection of saline or SRIF plus a s.c. injection of vehicle $(0.1 \%$ albumin-saline $)$ or $10 \mu \mathrm{g} / \mathrm{kg}$ glucagon. Blood glucose was measured from tail-tip blood using a Glucometer at 0,15 , and $30 \mathrm{~min}$ after the glucagon (vehicle) injection. The glucose AUC was calculated as described previously.

\section{Blood glucose measurements in the presence of exendin(9-39) in mice}

Male $B A L B / c$ mice were fasted overnight and then given a s.c. injection of vehicle or various doses of PEG-DAPD or FA-GLP-1, as well as a s.c. injection of PBS or exendin(9-39) $(100 \mu \mathrm{g} / \mathrm{kg})$. The exendin(9-39) or PBS injection was repeated 1 and $2 \mathrm{~h}$ later. Three hours after the initial injections, fasting blood glucose was measured from tail-tip blood using a Glucometer. The mice were then given an i.p. injection of $2 \mathrm{~g} / \mathrm{kg}$ glucose and blood glucose measured 15 , 30,60 , and $90 \mathrm{~min}$ later.

\section{Blood glucose in $\mathrm{db} / \mathrm{db}$ mice}

Female $d b / d b$ mice C57BLKS/J Lepr ${ }^{\mathrm{db}} /$ Lepr $^{\mathrm{db}}$ (6 weeks old) were fasted overnight and then treated as described under IPGTT. Following the IPGTT, the mice were grouped according to their glucose AUCs and given a s.c. injection of vehicle (PBS), 10 or $30 \mu \mathrm{g} / \mathrm{kg}$ PEG-DAPD. The mice were injected every other day for 2 weeks. Fasting blood glucose was measured $24 \mathrm{~h}$ after dosing at 7 and 8 weeks of age.

The blood glucose of 10-week-old female $d b / d b$ mice was determined as described and the mice with equivalent mean values were grouped together. The mice were fasted overnight and their fasting blood glucose determined. The mice were given a s.c. injection of either vehicle (PBS), PEGDAPD $(30 \mu \mathrm{g} / \mathrm{kg})$, or FA-GLP-1 $(30 \mu \mathrm{g} / \mathrm{kg})$ daily for 2 weeks. Both fed and fasting blood glucose were measured $24 \mathrm{~h}$ after dosing at 11 and 12 weeks.

\section{Statistical analysis}

Data are expressed as means \pm s.E.M. for the number of animals/group indicated. Statistical analyses were performed using GraphPad InStat (GraphPad software, Inc., San Diego, CA, USA). Treatment effects were analyzed by ANOVA with post hoc analysis using Tukey-Kramer Multiple Comparisons test (parametric methods) or Kruskal-Wallis test (non-parametric methods) when necessary. Differences are considered significant at $P$ values $<0 \cdot 05$.

\section{Results}

Glucose lowering efficacy and gastrointestinal motility in mice

The ability of PEG-DAPD (PEGylated with $43 \mathrm{kDa}$ branched PEG) to increase insulin and decrease glucose in vivo was examined by performing an IPGTT in mice $3 \mathrm{~h}$ after peptide administration by s.c. injection. PEG-DAPD $(30 \mu \mathrm{g} / \mathrm{kg})$ causes a significant increase in insulin levels, with an $88 \pm 16 \%$ increase in the insulin AUC (Fig. 1a and b). There is a corresponding decrease in glucose, with a $50 \pm 2 \%$ decrease in the glucose AUC (Fig. 1c and d).

DAPD, PEG-DAPD, and FA-GLP-1 (fatty acid modified GLP-1, equivalent to Novo Nordisk's NN2211/liraglutide) were then examined for their ability to lower blood glucose following an IPGTT administered either 3 or $17 \mathrm{~h}$ after s.c. administration of $100 \mu \mathrm{g} / \mathrm{kg}$ peptide in mice (Fig. 2). When the IPGTT is performed $3 \mathrm{~h}$ after peptide administration DAPD, PEG-DAPD, and FA-GLP-1 reduce blood glucose, with decreases in the glucose AUC of $20 \pm 6,40 \pm 6$, and $29 \pm$ $2 \%$ respectively (Fig. $2 \mathrm{a}$ and c). Non-modified GLP-1 has a half-life in vivo of $<5 \mathrm{~min}$ and, as expected, is inactive in an IPGTT performed $3 \mathrm{~h}$ following peptide administration (data not shown). PEG-DAPD reduces the glucose AUC to a greater extent than DAPD, indicating prolonged activity. The prolonged activity of PEG-DAPD is further demonstrated by its ability to reduce blood glucose, with a decrease in the glucose AUC of $48 \pm 5 \%$, when the IPGTT is performed $17 \mathrm{~h}$ following s.c. administration (Fig. $2 \mathrm{~b}$ and c). This is consistent with the observation that the level of PEG-DAPD measured in plasma samples 3 and $17 \mathrm{~h}$ after s.c. administration of $100 \mu \mathrm{g} /$ $\mathrm{kg}$ is 172 and $124 \mathrm{nM}$ respectively. Neither FA-GLP-1 nor non-PEGylated DAPD has any significant effect on the glucose AUC at $17 \mathrm{~h}$ due to the short half-life of both peptides in vivo.

FA-GLP-1 causes a dose-dependent decrease in the glucose AUC during an IPGTT performed $3 \mathrm{~h}$ following peptide administration, with an $\mathrm{ED}_{50}$ of $34 \mu \mathrm{g} / \mathrm{kg}$ and a maximal decrease in the glucose AUC of $34 \pm 1 \% 3$ (Fig. 3a). PEGDAPD also causes a dose-dependent decrease in the glucose AUC, with an $\mathrm{ED}_{50}$ of $7 \mu \mathrm{g} / \mathrm{kg}$ and a maximal decrease in the glucose AUC of $47 \pm 1 \%(P<0 \cdot 0001$ versus FA-GLP-1; Fig. $3 \mathrm{~b})$. Therefore, PEG-DAPD is more potent and more efficacious than FA-GLP-1.

The effect of FA-GLP-1 and PEG-DAPD on GI motility was also examined in mice. As expected, FA-GLP-1 decreases GI motility with a potency similar to its effect in the IPGTT. FA-GLP-1 significantly decreases GI motility by $16 \pm 1$ and $33 \% \pm 4 \%$ at doses of 30 and $100 \mu \mathrm{g} / \mathrm{kg}$ respectively (Fig. 3a). Unlike FA-GLP-1, PEG-DAPD (PEGylated with $43 \mathrm{kDa}$ branched PEG) has no significant effect on GI motility in the mouse at doses up to $100 \mu \mathrm{g} / \mathrm{kg}$ (Fig. 3b). However, DAPD 
(a)

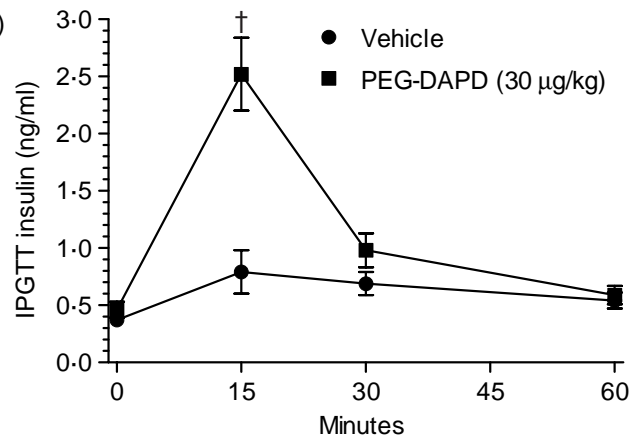

(b)

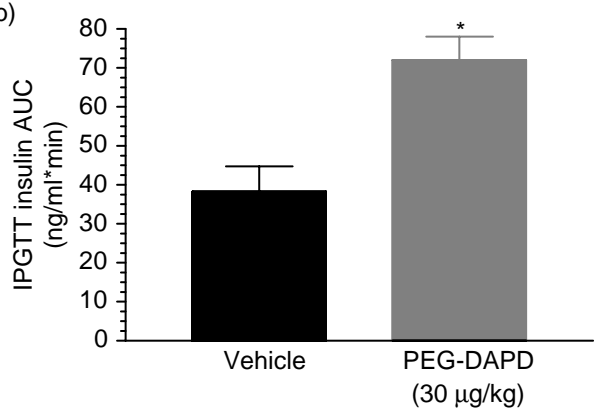

(c)
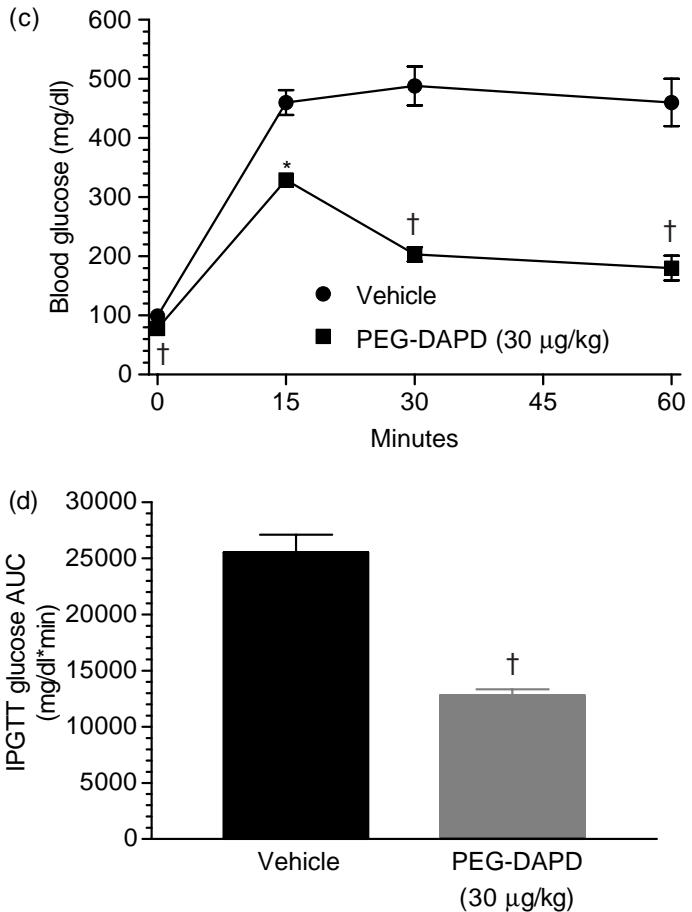

Figure 1 Insulin increasing and glucose lowering activity in an IPGTT in mice. Overnight fasted $B A L B / C$ mice were injected subcutaneously with vehicle or $30 \mu \mathrm{g} / \mathrm{kg}$ PEG-DAPD and $3 \mathrm{~h}$ later an IPGTT was performed. The effect of PEG-DAPD on plasma insulin (a), insulin AUC (b), plasma glucose (c), and glucose AUC (d) was measured. Data are means \pm s.E.M. for 8-16 mice/group. ${ }^{*} P<0 \cdot 01$ and ${ }^{\dagger} P<0 \cdot 001$.
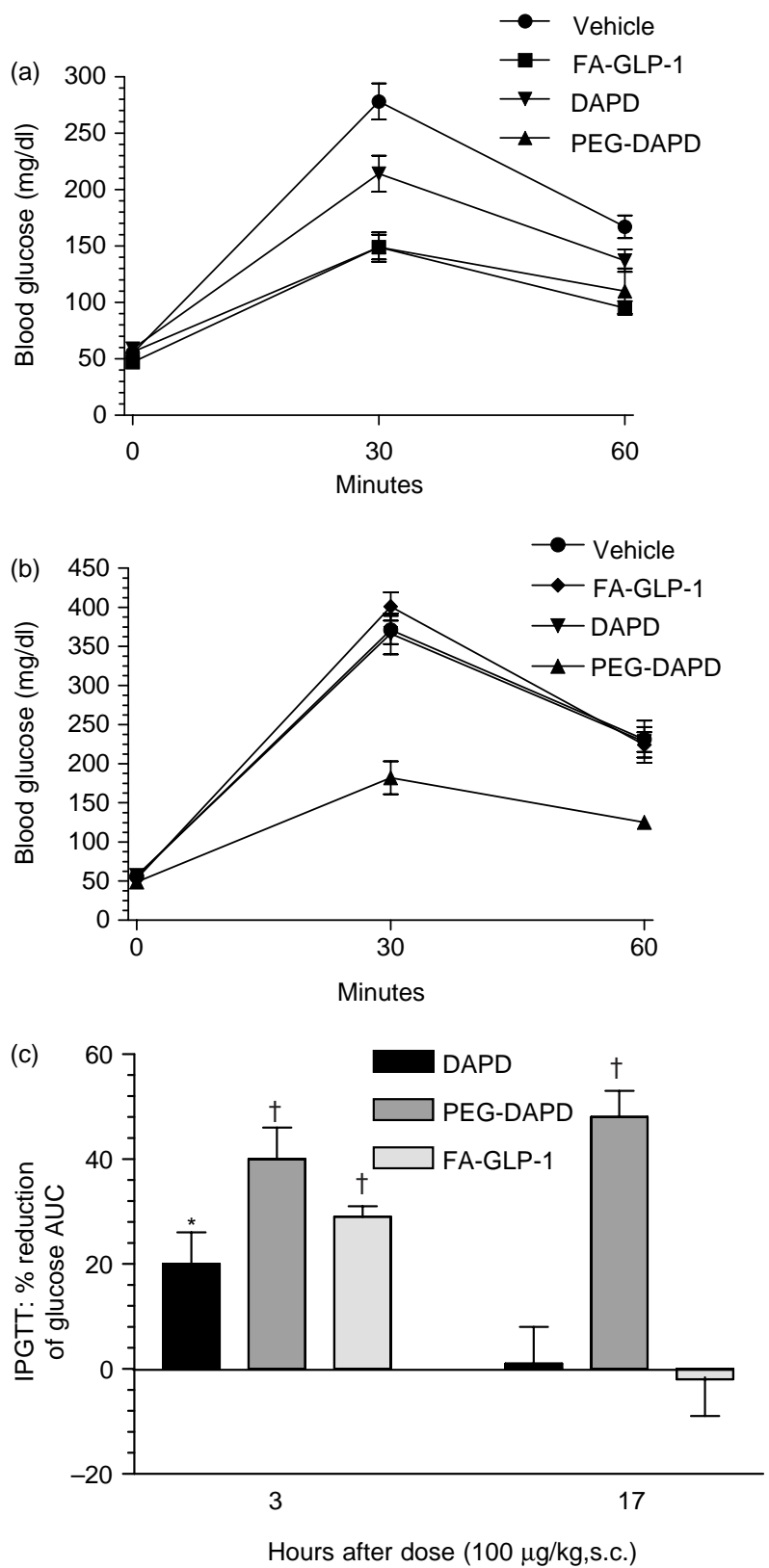

Figure 2 Glucose lowering activity in an IPGTT in mice. Overnight fasted $B A L B / C$ mice were injected subcutaneously with vehicle or $100 \mu \mathrm{g} / \mathrm{kg}$ FA-GLP-1, PEG-DAPD or DAPD, and either $3 \mathrm{~h}$ (a) or $17 \mathrm{~h}$ (b) later an IPGTT was performed. The glucose AUC was determined and the percentage reduction due to each treatment was calculated (c). Data are means \pm S.E.M. for 8-16 mice/group. $* P<0 \cdot 05$ and ${ }^{+} P<0 \cdot 001$.

PEGylated with a linear $22 \mathrm{kDa}$ PEG inhibits GI motility with a potency similar to that of FA-GLP-1 (Fig. 3c). DAPD PEGylated with a linear $33 \mathrm{kDa}$ PEG inhibits GI motility to a degree intermediate between that of 22 and $43 \mathrm{kDa}$ PEGylated DAPD. GLP-1 PEGylated with linear 22 kDa PEG inhibits GI motility with a potency similar to that of FA-GLP-1. Similar to 

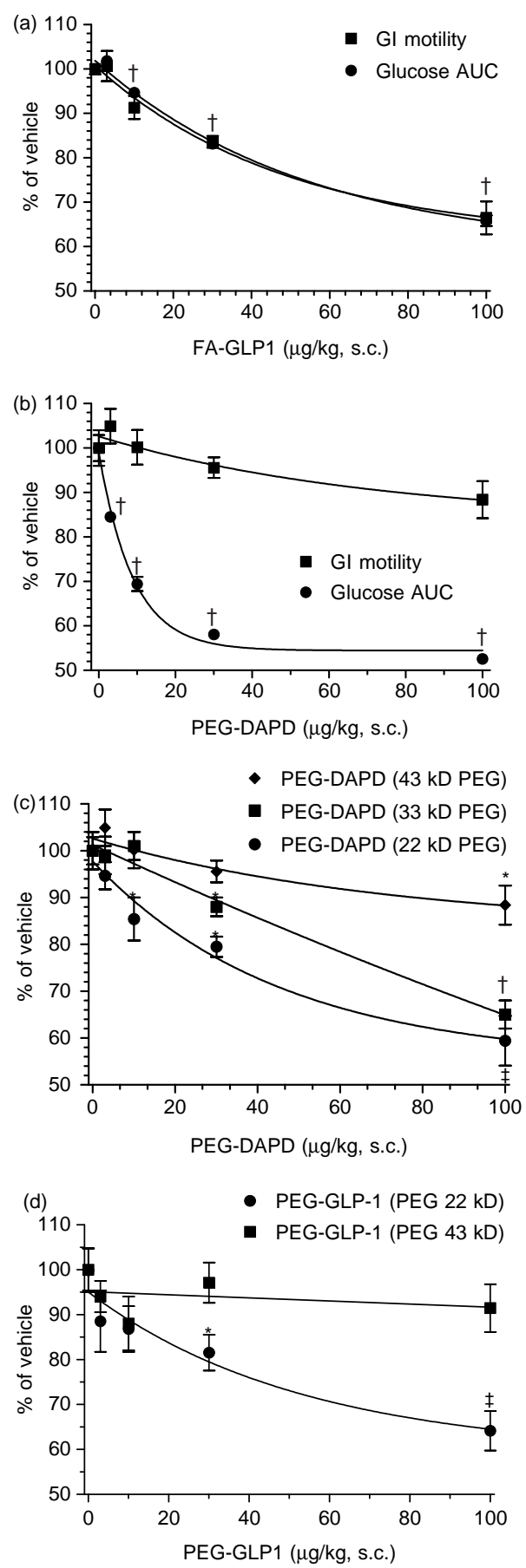

Figure 3 Dose response analysis of glucose lowering activity and gastrointestinal motility effects in mice. Effect of FA-GLP-1 (a) or PEG-DAPD (b) on gastrointestinal motility $(\boldsymbol{\square})$ and glucose AUC (-) in $B A L B / C$ mice $3 \mathrm{~h}$ after peptide administration. Effect of DAPD (c) or GLP-1 (d) PEGylated with PEGs of different molecular mass on gastrointestinal motility in $B A L B / C$ mice $3 \mathrm{~h}$ after peptide administration. Data are means \pm s.E.M. for six mice/group. ${ }^{*} P<0 \cdot 05$, ${ }^{+} P<0 \cdot 01$ and ${ }^{\ddagger} P<0 \cdot 001$.
DAPD, GLP-1 PEGylated with branched 43 kDa PEG has no significant effect on GI motility (Fig. 3d).

\section{Glucose lowering efficacy and gastrointestinal motility in rats}

The effect of PEG-DAPD on glucose tolerance and GI motility was also examined in rats (Fig. 4). PEG-DAPD causes a dose-dependent decrease in blood glucose in an IPGTT performed $17 \mathrm{~h}$ after s.c. administration of the peptide. The decrease in the glucose AUC is $11 \pm 3$ and $19 \pm 6 \%$ at doses of 1 and $3 \mu \mathrm{g} / \mathrm{kg}$ respectively. A maximal decrease in the glucose AUC is observed at a dose of $3 \mu \mathrm{g} / \mathrm{kg}$ as similar decreases are observed at doses up to $100 \mu \mathrm{g} / \mathrm{kg}$ (Fig. 4a). Therefore, PEGDAPD is more potent, but less efficacious, in an IPGTT in rats when compared with mice, as is FA-GLP-1 (data not shown). PEG-DAPD has no significant effect on GI motility in rats at doses up to $100 \mu \mathrm{g} / \mathrm{kg}$ (Fig. 4a), whereas FA-GLP-1 decreases GI motility in rats with efficacy and potency similar to its effect in an IPGTT (data not shown).
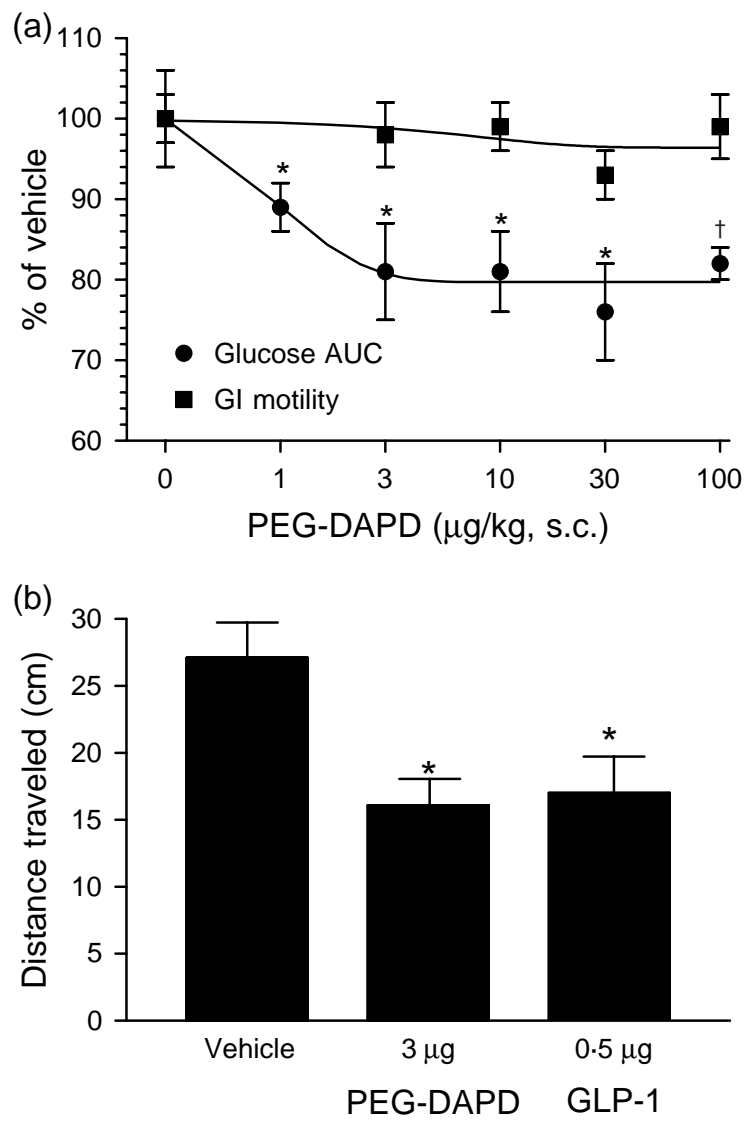

Figure 4 Glucose lowering activity and gastrointestinal motility effects in rats. (a) Effect of PEG-DAPD on glucose AUC in an IPGTT in fasted Wistar rats $(-)$ and on gastrointestinal motility $(\boldsymbol{\square}) 17 \mathrm{~h}$ after peptide administration. The data are means \pm s.E.M. for eight and six rats/group respectively. (b) Effect of CNS administered PEGDAPD and GLP-1 on gastrointestinal motility. The data are means \pm S.E.M. for ten rats/group. ${ }^{*} P<0 \cdot 05$ and ${ }^{\dagger} P<0 \cdot 01$. 
An IPGTTwas performed at 17, 41, 65, and $89 \mathrm{~h}$ following s.c. administration of a single $30 \mu \mathrm{g} / \mathrm{kg}$ dose of PEG-DAPD in rats. PEG-DAPD administration up to $65 \mathrm{~h}$ prior to the IPGTT results in a significant decrease in the glucose AUC (Table 1). There is also a trend towards a decrease at $89 \mathrm{~h}$ after dosing. These results demonstrate that PEG-DAPD has dramatically prolonged activity when compared with nonmodified GLP-1 because of the improved stability and reduced clearance of the PEGylated peptide.

Attachment of a $43 \mathrm{kDa}$ PEG (branched) to DAPD may restrict its ability to cross the blood-brain barrier and thereby account for its inability to affect GI motility. In support of this hypothesis, central administration of $3 \mu \mathrm{g} / \mathrm{kg}$ PEG-DAPD by intracerebroventricular (i.c.v.) injection results in a significant reduction in GI motility, similar to that observed with $0 \cdot 5 \mu \mathrm{g} / \mathrm{kg} \mathrm{GLP}-1$ (Fig. 4b).

\section{Inhibition of glucagon action in mice}

PEG-DAPD could mediate a reduction in the glucagoninduced increase in blood glucose by either direct glucagon receptor antagonism, indirectly through enhanced insulin secretion from the pancreas, or a combination of both. Glucagon antagonist activity of PEG-DAPD in vivo was examined first by performing a glucagon challenge in mice and comparing the activity of PEG-DAPD with that of PEGGLP-1 (GLP-1 PEGylated with 43 kDa PEG) on blood glucose levels. PEG-GLP-1 acts specifically as a GLP-1 receptor agonist and does not have glucagon antagonist activity. PEG-DAPD $(10 \mu \mathrm{g} / \mathrm{kg})$ significantly suppresses the glucagon-induced increase in blood glucose AUC, whereas PEG-GLP-1 at the same dose has no effect (Fig. 5a). This indicates that PEG-DAPD has glucagon antagonist activity in vivo and it is likely to be, at least in part, directly on the glucagon receptor. In order to explore further the direct glucagon receptor antagonist activity of PEG-DAPD, a glucagon challenge was performed in the presence of $10 \mathrm{mg} / \mathrm{kg}$ somatostatin (SRIF), which inhibits pancreatic insulin secretion. PEG-DAPD significantly reduces the glucagon-mediated increase in the glucose AUC (Fig. 5b), whereas PEG-GLP-1 has no significant effect (Fig. 5c). We conclude that the PEG-DAPD mediated reduction in glucose levels in a glucagon challenge reflects direct glucagon receptor antagonist activity in vivo.

Table 1 Glucose lowering efficacy of PEG-DAPD in rats when administered subcutaneously $(30 \mu \mathrm{g} / \mathrm{kg})$ at increasing lengths of time prior to an IPGTT. The data are the means \pm s.E.M. of 9-16 rats/group

\section{Hours after dosing PEG-DAPD}

\begin{tabular}{|c|c|c|c|c|}
\hline & $17 \mathrm{~h}$ & $41 \mathrm{~h}$ & $65 \mathrm{~h}$ & $89 \mathrm{~h}$ \\
\hline Efficacy & $24 \pm 5$ & $17 \pm 2$ & $18 \pm 2$ & $11 \pm 4$ \\
\hline$P$ value & $0 \cdot 001$ & 0.0005 & $0 \cdot 0017$ & $0 \cdot 0905$ \\
\hline
\end{tabular}

Efficacy, \% reduction of glucose AUC.

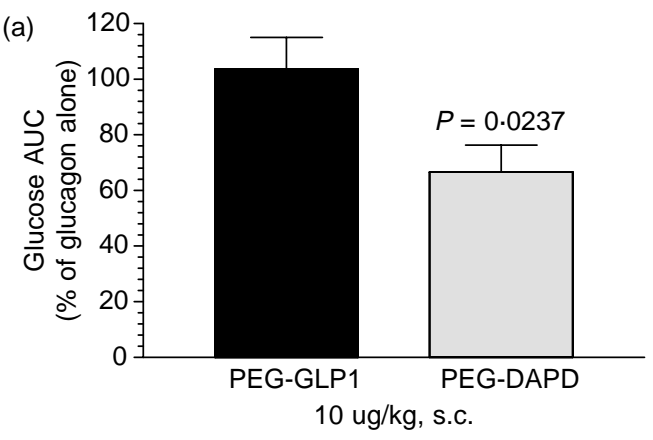

$\dagger$
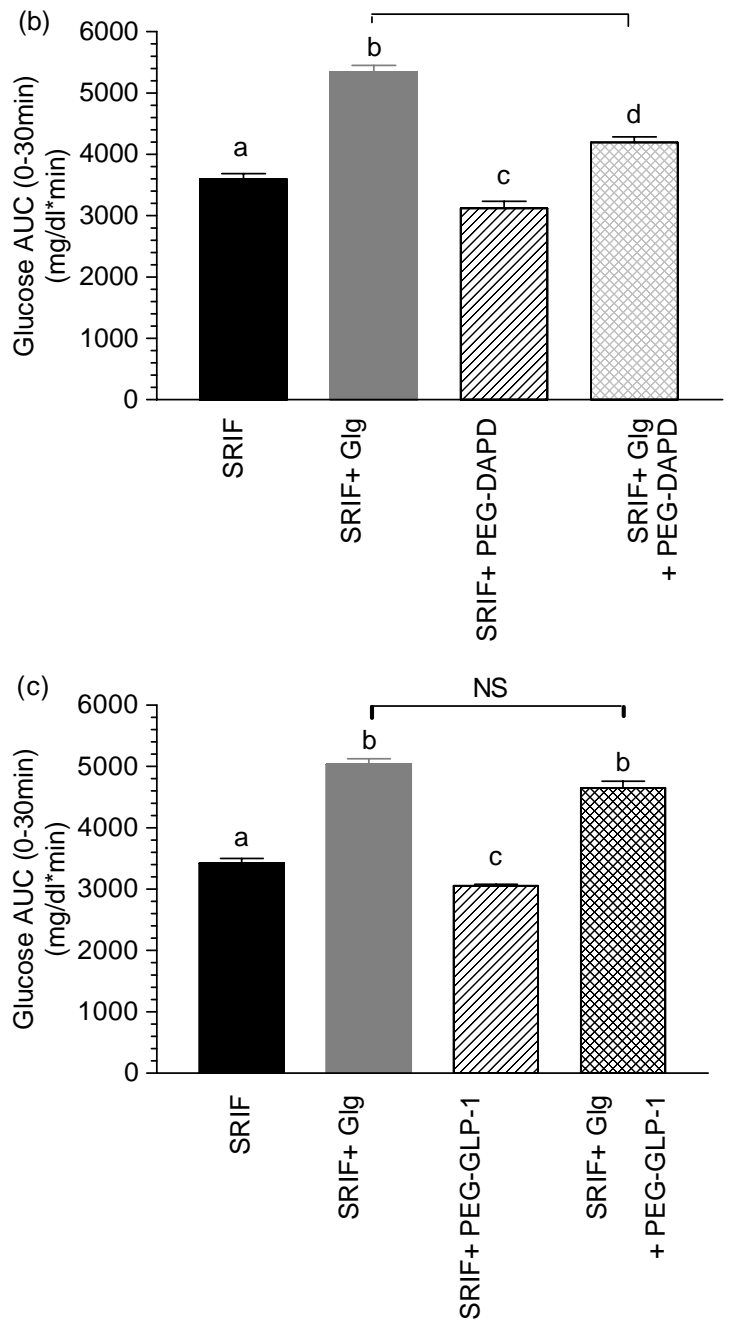

Figure 5 Effect of PEG-DAPD and PEG-GLP-1 on glucagon induced increase in blood glucose in mice. $B A L B / C$ mice were treated $3 \mathrm{~h}$ prior to a glucagon (GIg) challenge with either vehicle, PEG-DAPD $(10 \mu \mathrm{g} / \mathrm{kg})$ or PEG-GLP-1 (10 $\mu \mathrm{g} / \mathrm{kg})$ in the absence (a) or presence (b and c) of somatostatin (SRIF). Somatostatin was administered $15 \mathrm{~min}$ prior to, and again at the time of, the glucagon challenge. Data are means \pm S.E.M. of 12 mice/group. ${ }^{\dagger} P<0 \cdot 001$, NS, not significant. Bars with different letters are significantly different from each other $(P<0 \cdot 05$ or less $)$. 
Plasma glucagon levels and effect of exendin(9-39) on blood glucose in mice

In order to further assess the glucagon receptor antagonist activity of PEG-DAPD in vivo plasma glucagon levels were measured in mice $3 \mathrm{~h}$ following PEG-DAPD administration. PEG-DAPD significantly increases plasma glucagon levels at all doses tested (Fig. 6a). This is consistent with reports that knockdown of glucagon receptor expression leads to an increase in plasma glucagon levels (Parker et al. 2002, Gelling et al. 2003, Liang et al. 2004, Sloop et al. 2004). On the other hand, GLP-1 agonism decreases glucagon secretion (Nauck et al. 1993). Unlike PEG-DAPD, FA-GLP-1 does not significantly affect glucagon levels, although there is a trend towards a decrease at the $100 \mu \mathrm{g} / \mathrm{kg}$ dose (Fig. 6a).

Exendin(9-39) acts as an antagonist of the GLP-1 receptor (Kolligs et al. 1995). The effect of exendin(9-39) on the ability of PEG-DAPD and FA-GLP-1 to lower blood glucose during an IPGTT also was examined (Fig. 6b). The PEG-DAPD mediated decrease in the glucose AUC at 10 and $30 \mu \mathrm{g} / \mathrm{kg}$ is only partially reversed by exendin(9-39). This supports a role for glucagon antagonism, as well as GLP-1 agonism, in the reduction of the glucose AUC. PEG-DAPD at $100 \mu \mathrm{g} / \mathrm{kg}$ overcomes the inhibitory effect of exendin(9-39). Exendin(9-39) almost completely inhibited the effect of FA-GLP-1, except at the $200 \mu \mathrm{g} / \mathrm{kg}$ dose. As in the absence of exendin(9-39) (Fig. 3), the maximum decrease in the glucose AUC obtained with PEG-DAPD $(47 \pm 1 \%)$ is greater than that obtained with FA-GLP-1 (34 $\pm 1 \% ; P<0 \cdot 0001)$. The results support the conclusion that PEG-DAPD affects glucose homeostasis beyond that which occurs through GLP1 receptor activation.

\section{Glucose lowering efficacy in $\mathrm{db} / \mathrm{db}$ mice}

Obese diabetic $(d b / d b)$ mice begin to display fasting hyperglycemia at about 8 weeks of age. In order to determine whether PEG-DAPD prevents or delays the onset of hyperglycemia, 6-week-old prediabetic female $d b / d b$ mice were dosed subcutaneously with 10 or $30 \mu \mathrm{g} / \mathrm{kg}$ PEG-DAPD for 2 weeks. Fasting blood glucose levels in the vehicle-treated mice began to rise between 7 and 8 weeks of age, and PEG-DAPD prevented the increase (Fig. 7a). Therefore, PEG-DAPD delays the onset of hyperglycemia in young $d b / d b$ mice. PEG-DAPD also produces a significant decrease in fasting blood glucose in 10-12-week-old diabetic $d b / d b$ mice, while FA-GLP-1 treatment does not, although there was a trend towards a decrease (Fig. 7b). Neither PEG-DAPD nor FA-GLP-1 has any effect on fed blood glucose levels (data not shown).

\section{Discussion}

We have identified a novel PEGylated GLP-1 agonist/glucagon antagonist peptide (PEG-DAPD) with a number of attractive features. First, it has both GLP-1 agonist and (a)
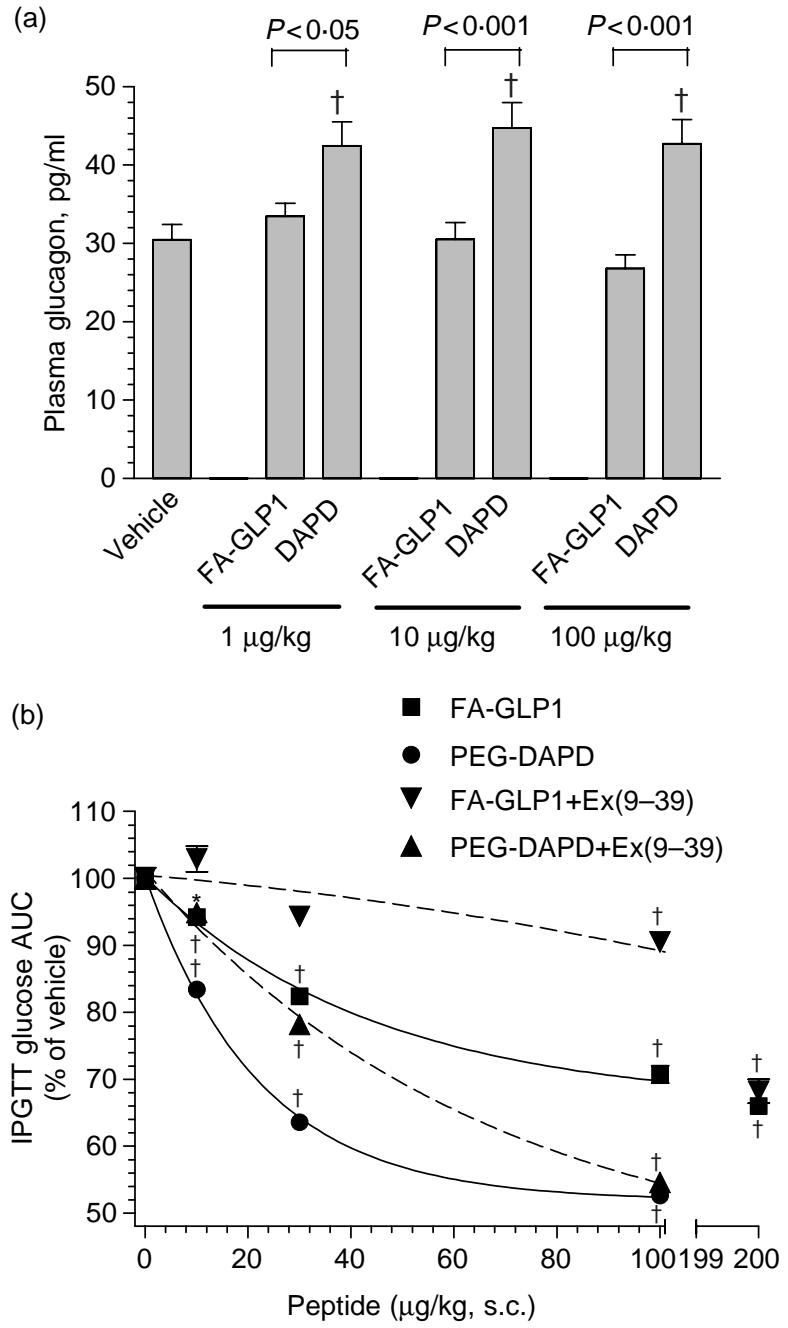

Figure 6 Effect of PEG-DAPD and FA-GLP-1 on plasma glucagon and blood glucose in the presence of exendin(9-39) in mice. Overnight fasted $B A L B / C$ mice were treated with either vehicle, PEG-DAPD or FA-GLP-1 $3 \mathrm{~h}$ prior to measurement of plasma glucagon levels (a), or blood glucose in an IPGTT in the presence or absence of exendin(9-39) (Ex (9-39)) (b). Data are means \pm s.E.M. of 8-16 mice/group. ${ }^{*} P<0 \cdot 05$ and ${ }^{+} P<0 \cdot 01$. In (a) the $P$ values indicated by + refers to PEG-DAPD versus vehicle and the $P$ values shown in the figure refer to PEG-DAPD versus FA-GLP-1 (same dose).

glucagon antagonist activity to lower blood glucose levels. Secondly, through PEGylation and elimination of the DPPIV cleavage site, the peptide has prolonged activity in vivo. Thirdly, PEGylation with high molecular mass $(43 \mathrm{kDa})$ branched PEG eliminates the inhibitory effect on GI motility normally associated with GLP-1, and which is likely to be related to the nausea and vomiting in humans reported with existing GLP-1 agonists (for review, see Drucker 2006).

The properties of GLP-1 make it attractive as a potential therapy for the treatment of type 2 diabetes. Infusion of GLP1 is effective in lowering blood glucose, even in diabetic 

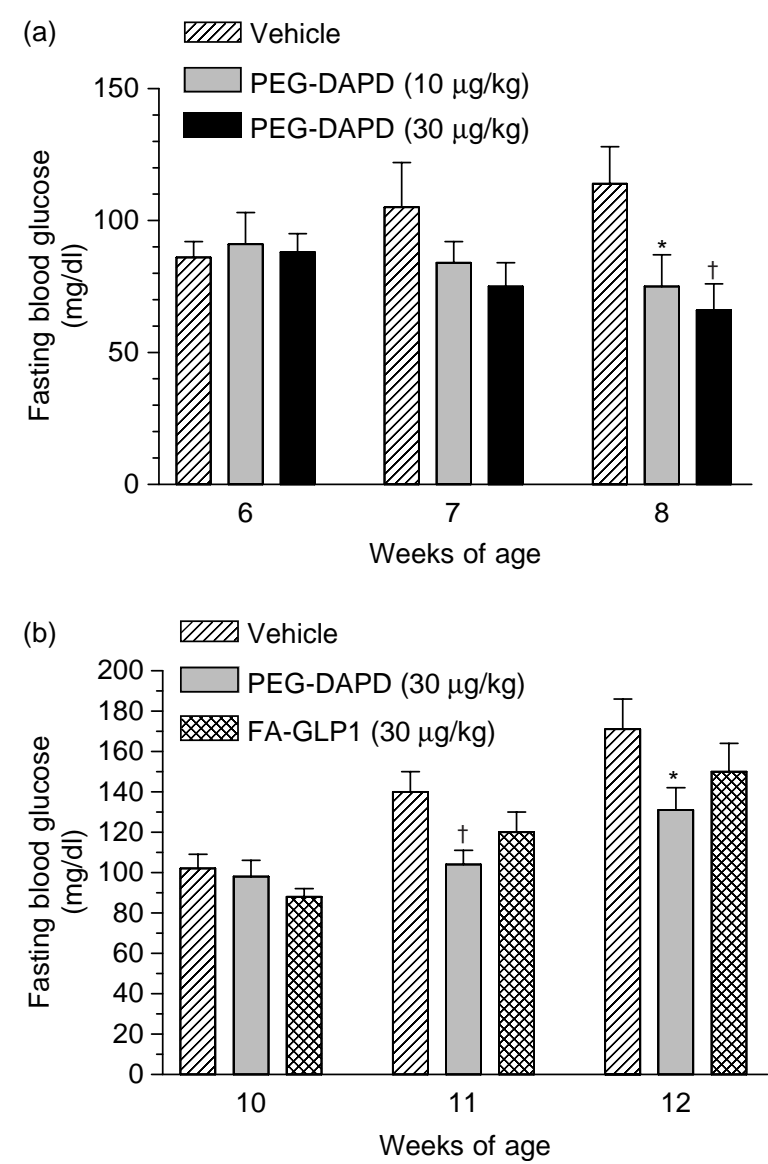

Figure 7 Effect of PEG-DAPD blood glucose in $d b / d b$ mice. (a) Prediabetic $d b / d b$ mice were dosed every other day and fasting blood glucose was measured weekly. (b) Diabetic $d b / d b$ mice were dosed daily and fasting blood glucose was measured weekly. The fasting glucose values are means \pm s.E.M. for $6-8$ mice per group. ${ }^{*} P<0.05$ and ${ }^{\dagger} P<0 \cdot 01$ versus vehicle.

patients who have failed on SFUs (Rachman et al. 1997, Nauck et al. 1998, Toft-Nielsen et al. 1999, Zander et al. 2002). In addition to promoting glucose-dependent insulin secretion, with little risk of hypoglycemia, GLP-1 also has the potential to preserve $\beta$-cell function and delay or even prevent disease progression (Stoffers et al. 2000, Egan et al. 2003). A GLP-1 analogue is already available for the treatment of type 2 diabetes (Exenatide/Byetta), and others are presently in various stages of development (for review, see Knudsen 2004). These analogues are aimed primarily at overcoming the very short half-life of GLP-1 in vivo. Exenatide (Byetta) is administered twice daily as a s.c. injection and demonstrates glucose lowering activity in type 2 diabetics (Fineman et al. 2003, Kolterman et al. 2003). Transient nausea has also been reported (Blonde et al. 2006).

In addition to the GLP-1 agonist activity of PEG-DAPD, its ability to suppress glucagon action is another important property of this peptide. Several lines of evidence support the glucagon antagonism of PEG-DAPD in vivo. It reduces blood glucose following a glucagon challenge, and elevates fasting glucagon levels. The effects of PEG-DAPD on glucose tolerance are also observed in the presence of the GLP-1 receptor antagonist, exendin(9-39). The effect of PEGDAPD to reduce blood glucose following a glucagon challenge is also observed in the presence of SRIF, which blocks insulin secretion. It has been demonstrated that the reduction in expression of the glucagon receptor, using an antisense oligonucleotide approach, leads to a reduction in blood glucose levels and improved glucose tolerance (Liang et al. 2004, Sloop et al. 2004). Small molecule glucagon receptor antagonists have been pursued as an approach to treat type 2 diabetes. The most advanced compound reported to date, BAY 27-9955, lowers plasma glucose levels during a hyperglucagonemic period in humans (Petersen \& Sullivan 2001). Peptide antagonists of the glucagon receptor have also been described but they have short half-lives in vivo (for review, see Sloop \& Michael 2004).

Plasma glucagon levels are elevated in $d b / d b$ mice and glucagon plays an important role in their age-associated development of hyperglycemia (Kodama et al. 1994). The ability of PEG-DAPD to delay the onset of hyperglycemia in pre-diabetic $d b / d b$ mice and to lower the fasting blood glucose levels in diabetic $d b / d b$ mice supports the dual-acting role of PEG-DAPD to increase insulin secretion and inhibit glucagon action. Other GLP-1 analogues have been reported to lower blood glucose in fed $d b / d b$ mice (Rolin et al. 2002, Kim et al. 2003). We believe that the effects observed on fed glucose levels in $d b / d b$ mice may be a consequence of the effects of these GLP-1 analogues on food intake at the high doses administered. Alternatively, a recent report suggests that during hyperglycemia central GLP-1 activity plays a role in control of blood glucose (Knauf et al. 2005). The present data indicate that PEG-DAPD cannot cross the blood-brain barrier, thus PEG-DAPD may have GLP-1 signaling activity distinct from other GLP-1 analogues to control blood glucose.

PEGylation is an established approach for improving the pharmacokinetic and pharmacodynamic properties of protein pharmaceuticals. The PEG polymer protects the attached protein from enzyme degradation and rapid renal clearance, thereby prolonging the in vivo half-life. PEG also reduces interactions with cell surface proteins, thereby limiting adverse immunological effects. As a consequence, a number of PEGylated protein drugs have been approved with properties that lead to significant clinical benefits, such as sustained blood levels, reduced adverse reactions, and improved patient convenience (for review, see Harris \& Chess 2003). While proteins that have been PEGylated with high molecular weight $\mathrm{PEG}$ and that retain significant in vivo activity have been reported, we believe PEG-DAPD represents the first reported PEGylation of a small peptide that retains prolonged in vivo activity.

PEG-DAPD was efficacious for as long as $65 \mathrm{~h}$ after a single s.c. dose in rats. Therefore, PEG-DAPD could have the potential for infrequent dosing in humans. Given the high prevalence of gastric motility disorders in patients with 
diabetes, further inhibition of gastric emptying in these patients is likely to exacerbate symptoms of nausea and vomiting (Horowitz et al. 2002). Furthermore, delaying gastric emptying may also alter the pharmacokinetic properties of other medications. PEG-DAPD did not inhibit GI motility when given subcutaneously, but did when given centrally to rats. This supports the hypothesis that PEGDAPD does not cross the blood-brain barrier, and thereby prevents the peptide from interacting with brain GLP-1 receptors, which mediate, at least in part, the effects on GI motility. The absence of effects of PEG-DAPD on GI motility, if confirmed in humans, has the potential to be of benefit in the clinical setting.

It is reported that the GLP-1 mediated delay in gastric emptying, thereby slowing nutrient entry into the circulation, is an important component of its overall effect on postprandial glucose homeostasis (Nauck et al. 1997, Meier et al. 2005). As PEG-DAPD does not inhibit GI motility, it does not have the capability to lower glucose by this mechanism. However, the efficacy of PEG-DAPD in the animal models tested indicates that the glucose lowering activity of PEGDAPD is at least equivalent, if not superior, to that of FA-GLP-1. Therefore, the absence of glucose lowering by the GI-inhibitory mechanism with PEG-DAPD is most likely compensated for by the glucose lowering arising through its glucagon antagonist action.

With the increasing prevalence of type 2 diabetes and the limitations of the currently available therapies, there is a clear need for new and effective approaches to treat this disease. PEG-DAPD, by acting on two key pathways central to control of glucose homeostasis, GLP-1 and glucagon signaling, potentially represents such an approach. Furthermore, PEGylation, in addition to dramatically prolonging the in vivo activity of PEG-DAPD, most likely restricts its access to the central nervous system, thereby eliminating centrally mediated GI effects. Overall, PEG-DAPD has several attractive features which justify pursuing it as a potential treatment of type 2 diabetes.

\section{Acknowledgements}

We thank all members of the Bayer HealthCare Department of Diabetes Research and Bayer HealthCare Biotechnology for their support and contributions to this work. In particular, we would like to thank Irene Tom, Jian Zhu, Stephanie Yung, Lucinda Milardo, and Friedrich Jekat. The authors declare that there is no conflict of interest that would prejudice the impartiality of this scientific work.

\section{References}

Baron AD, Schaeffer L, Shragg P \& Kolterman OG 1987 Role of hyperglucagonemia in maintenance of increased rates of hepatic glucose output in type II diabetics. Diabetes 36 274-283.
Blonde L, Klein EJ, Han J, Zhang B, Mac SM, Poon TH, Taylor KL, Trautmann ME, Kim DD \& Kendall DM 2006 Interim analysis of the effects of exenatide treatment on A1C, weight and cardiovascular risk factors over 82 weeks in 314 overweight patients with type 2 diabetes. Diabetes, Obesity and Metabolism 8 436-447.

Buse JB, Henry RR, Han J, Kim DD, Fineman MS \& Baron AD 2004 Effects of exenatide (exendin-4) on glycemic control over 30 weeks in sulfonylurea-treated patients with type 2 diabetes. Diabetes Care $\mathbf{2 7}$ $2628-2635$.

Drucker DJ 2006 The biology of incretin hormones. Cell Metabolism 3 153-165.

Egan JM, Bulotta A, Hui H \& Perfetti R 2003 GLP-1 receptor agonists are growth and differentiation factors for pancreatic islet beta cells. Diabetes/Metabolism Research and Reviews 19 115-123.

Elbrond B, Jakobsen G, Larsen S, Agerso H, Jensen LB, Rolan P, Sturis J, Hatorp V \& Zdravkovic M 2002 Pharmacokinetics, pharmacodynamics, safety, and tolerability of a single-dose of NN2211, a long-acting glucagonlike peptide 1 derivative, in healthy male subjects. Diabetes Care $\mathbf{2 5}$ 1398-1404.

Fineman MS, Bicsak TA, Shen LZ, Taylor K, Gaines E, Varns A, Kim D \& Baron AD 2003 Effect on glycemic control of exenatide (synthetic exendin-4) additive to existing metformin and/or sulfonylurea treatment in patients with type 2 diabetes. Diabetes Care 26 2370-2377.

Gelling RW, Du XQ, Dichmann DS, Romer J, Huang H, Cui L, Obici S, Tang B, Holst JJ, Fledelius C et al. 2003 Lower blood glucose, hyperglucagonemia, and pancreatic alpha cell hyperplasia in glucagon receptor knockout mice. PNAS 100 1438-1443.

Harris JM \& Chess RB 2003 Effect of PEGylation on pharmaceuticals. Nature Reviews. Drug Discovery 2 214-221.

Harris JM, Martin NE \& Modi M 2001 Pegylation: a novel process for modifying pharmacokinetics. Clinical Pharmacokinetics 40 539-551.

Hjorth SA, Adelhorst K, Pedersen BB, Kirk O \& Schwartz TW 1994 Glucagon and glucagon-like peptide 1: selective receptor recognition via distinct peptide epitopes. Journal of Biological Chemistry 269 30121-30124.

Holst JJ 1996 Glucagon, glucagon-like peptide-1 and their receptors: an introduction. Acta Physiologica Scandinavica 157 309-315.

Holz GG, Kuhtreiber WM \& Habener JF 1993 Pancreatic beta-cells are rendered glucose-competent by the insulinotropic hormone glucagon-like peptide-1(7-37). Nature 361 362-365.

Horowitz M, O’Donovan D, Jones KL, Feinle C, Rayner CK \& Samsom M 2002 Gastric emptying in diabetes: clinical significance and treatment. Diabetic Medicine 19 177-194.

Imeryuz N, Yegen BC, Bozkurt A, Coskun T, Villanueva-Penacarrillo ML \& Ulusoy NB 1997 Glucagon-like peptide-1 inhibits gastric emptying via vagal afferent-mediated central mechanisms. American Journal of Physiology 273 G920-G927.

Jelinek LJ, Lok S, Rosenberg GB, Smith RA, Grant FJ, Biggs S, Bensch PA, Kuijper JL, Sheppard PO, Sprecher CA et al. 1993 Expression cloning and signaling properties of the rat glucagon receptor. Science 259 1614-1616.

Kieffer TJ \& Habener JF 1999 The glucagon-like peptides. Endocrine Reviews 20 876-913.

Kieffer TJ, McIntosh CH \& Pederson RA 1995 Degradation of glucosedependent insulinotropic polypeptide and truncated glucagon-like peptide 1 in vitro and in vivo by dipeptidyl peptidase IV. Endocrinology 136 3585-3596.

Kim J-G, Baggio LL, Bridon DP, Castaigne J-P, Robitaille MF, Jette L, Benquet C \& Drucker DJ 2003 Development and characterization of a glucagon-like peptide 1-albumin conjugate. Diabetes 52 751-759.

Knauf C, Cani PD, Perrin C, Iglesias MA, Maury JF, Bernard E, Benhamed F, Gremeaux T, Drucker DJ, Kahn CR et al. 2005 Brain glucagon-like peptide- 1 increases insulin secretion and muscle insulin resistance to favor hepatic glycogen storage. Journal of Clinical Investigation 115 3554-3563.

Knudsen LB 2004 Glucagon-like peptide-1: the basis of a new class of treatment for type 2 diabetes. Journal of Medicinal Chemistry 47 4128-4134.

Kodama H, Fujita M, Yamazaki M \& Yamaguchi I 1994 The possible role of age-related increase in the plasma glucagon/insulin ratio in the enhanced hepatic gluconeogenesis and hyperglycemia in genetically diabetic $(C 57 B L / K s J-d b / d b)$ mice. Japanese Journal of Pharmacology 66 281-287. 
Kolligs F, Fehmann HC, Goke R \& Goke B 1995 Reduction of the incretin effect in rats by the glucagon-like peptide 1 receptor antagonist exendin(9-39) amide. Diabetes 44 16-19.

Kolterman OG, Buse JB, Fineman MS, Gaines E, Heintz S, Bicsak TA, Taylor K, Kim D, Aisporna M, Wang Y et al. 2003 Synthetic exendin-4 (exenatide) significantly reduces postprandial and fasting plasma glucose in subjects with type 2 diabetes. Journal of Clinical Endocrinology and Metabolism 88 3082-3089.

Liang Y, Osborne MC, Monia BP, Bhanot S, Gaarde WA, Reed C, She P, Jetton TL \& Demarest KT 2004 Reduction in glucagon receptor expression by an antisense oligonucleotide ameliorates diabetic syndrome in $d b / d b$ mice. Diabetes 53 410-417.

Meier JJ, Kemmeries G, Holst JJ \& Nauck MA 2005 Erythromycin antagonizes the deceleration of gastric emptying by glucagon-like peptide 1 and unmasks its insulinotropic effect in healthy subjects. Diabetes $\mathbf{5 4} 2212-2218$.

Nauck MA, Heimesaat MM, Orskov C, Holst JJ, Ebert R \& Creutzfeldt W 1993 Preserved incretin activity of glucagon-like peptide 1 (7-36 amide) but not of synthetic human gastric inhibitory polypeptide in patients with type-2 diabetes mellitus. Journal of Clinical Investigation 91 301-307.

Nauck MA, Niedereichholz U, Ettler R, Holst JJ, Orskov C, Ritzel R \& Schmiegel WH 1997 Glucagon-like peptide 1 inhibition of gastric emptying outweighs its insulinotropic effects in healthy humans. American Journal of Physiology 273 E981-E988.

Nauck MA, Sauerwald A, Ritzel R, Holst JJ \& Schmiegel W 1998 Influence of glucagon-like peptide 1 on fasting glycemia in type 2 diabetic patients treated with insulin after sulfonylurea secondary failure. Diabetes Care $\mathbf{2 1}$ 1925-1931.

Pan CQ, Buxton JM, Yung SL, Tom I, Yang L, Chen H, Macdougall M, Bell A Claus TH, Clairmont KB et al. 2006 Design of a long acting peptide functioning as both a glucagon-like peptide-1 receptor agonist and a glucagon receptor antagonist. Journal of Biological Chemistry 281 $12506-12515$.

Parker JC, Andrews KM, Allen MR, Stock JL \& McNeish JD 2002 Glycemic control in mice with targeted disruption of the glucagon receptor gene. Biochemical and Biophysical Research Communications $290839-843$.

Petersen KF \& Sullivan JT 2001 Effects of novel glucagon receptor antagonist (Bay 27-9955) on glucagon-stimulated glucose prodction in humans. Diabetologia 44 2018-2024.

Rachman J, Barrow BA, Levy JC \& Turner RC 1997 Near-normalisation of diurnal glucose concentrations by continuous administration of glucagonlike peptide-1 (GLP-1) in subjects with NIDDM. Diabetologia 40 205-211.

Rendell M 2004 The role of sulphonylureas in the management of type 2 diabetes mellitus. Drugs 64 1339-1358.
Rolin B, Larsen MO, Gotfredsen CF, Deacon CF, Carr RD, Wilken M \& Knudsen LB 2002 The long-acting GLP-1 derivative NN2211 ameliorates glycemia and increases beta-cell mass in diabetic mice. American Journal of Physiology. Endocrinology and Metabolism 283 E745-E752.

Shah P, Vella A, Basu A, Basu R, Schwenk WF \& Rizza RA 2000 Lack of suppression of glucagon contributes to postprandial hyperglycemia in subjects with type 2 diabetes mellitus. Journal of Clinical Endocrinology and Metabolism 85 4053-4059.

Sloop KW \& Michael MD 2004 Role of the glucagon receptor in glucose homeostasis: a therapeutic target to improve glycemic control in type 2 diabetes. Drugs of the Future 29 835-841.

Sloop KW, Cao JX, Siesky AM, Zhang HY, Bodenmiller DM, Cox AL, Jacobs SJ, Moyers JS, Owens RA, Showalter AD et al. 2004 Hepatic and glucagon-like peptide-1-mediated reversal of diabetes by glucagon receptor antisense oligonucleotide inhibitors. Journal of Clinical Investigation 113 1571-1581.

Stoffers DA, Kieffer TJ, Hussain MA, Drucker DJ, Bonner-Weir S, Habener JF \& Egan JM 2000 Insulinotropic glucagon-like peptide 1 agonists stimulate expression of homeodomain protein IDX-1 and increase islet size in mouse pancreas. Diabetes 49 741-748.

Toft-Nielsen MB, Madsbad S \& Holst JJ 1999 Continuous subcutaneous infusion of glucagon-like peptide 1 lowers plasma glucose and reduces appetite in type 2 diabetic patients. Diabetes Care 22 1137-1143.

Unger RH, Dobbs RE \& Orci L 1978 Insulin, glucagon, and somatostatin secretion in the regulation of metabolism. Annual Review of Physiology $\mathbf{4 0}$ 307-343.

Weber AE 2004 Dipeptidyl peptidase IV inhibitors for the treatment of diabetes. Journal of Medicinal Chemistry 47 4135-4141.

Wettergren A, Wojdemann M \& Holst JJ 1998 Glucagon-like peptide-1 inhibits gastropancreatic function by inhibiting central parasympathetic outflow. American Journal of Physiology 275 G984-G992.

Zander M, Madsbad S, Madsen JL \& Holst JJ 2002 Effect of 6 week course of glucagon-like peptide 1 on glycemic control, insulin sensitivity, and $\beta$-cell function in type 2 diabetes: a parallel-group study. Lancet 359 824-830.

Received in final form 13 November 2006

Accepted 16 November 2006

Made available online as an Accepted Preprint 17 November 2006 